\title{
Urinary 1-hydroxypyrene in occupationally-exposed and non-exposed individuals in Silesia, Poland
}

\author{
Joanna Zająç ${ }^{1, A, C-D, F}$, Ewa Gomółka ${ }^{2,3, B-C, F}$, Wojciech Szot ${ }^{1, A, C, E-F}$ \\ 1 Jagiellonian University Medical College, Department Hygiene and Dietetics, Kraków, Poland \\ 2 Toxicological Laboratory, Diagnostics Department, University Hospital, Kraków, Poland \\ ${ }^{3}$ Laboratory of Poison Information and Toxicological Analysis, Department of Toxicology and Environmental Disease, \\ Jagiellonian University Medical College, Kraków, Poland \\ A - Research concept and design, B - Collection and/or assembly of data, C - Data analysis and interpretation, \\ $D$ - Writing the article, E - Critical revision of the article, F - Final approval of article
}

Zając J, Gomółka E, Szot W. Urinary 1-hydroxypyrene in occupationally exposed and not exposed individuals in Silesia, Poland. Ann Agric Environ Med. 2018; 25(4): 625-629. doi: 10.26444/aaem/75940

\begin{abstract}
Introduction. The aim of presented study was comparison of urinary 1-hydroxypyrene concentration among coke plant workers (before and after working week) and among non-exposed individuals from the same area, taking smoking status into consideration.

Materials and method. 647 coke plant workers and 206 individuals living in the same area were analysed with respect to urinary 1-OHP concentration and smoking status. Urinary samples were measured using high performance liquid chromatography (HPLC) with fluorescent detection. Concentrations were normalized with respect to creatinine concentration. For workers, two samples were collected before and after working week. Multiple regression was performed to distinguish and quantify the influence of cigarette smoking and occupational PAH exposition on the urinary 1-OHP levels.

Results. Average urinary 1-OHP concentration of samples collected before the working week was: $1.07 \mu \mathrm{g} / \mathrm{g}$; after the working week: $2.36 \mu \mathrm{g} / \mathrm{g}$ and for control: $0.74 \mu \mathrm{g} / \mathrm{g}$. The samples collected at the beginning of the working week were not suitable for assessment of the workers' background (non-occupational) exposition. Smoking cigarettes induced a rise in urinary $1-\mathrm{OHP}$ level by $16 \%$, on average $(\mathrm{Cl}: 5 \%-28 \%)$, and working for a whole working week at the coke plant made urinary 1-OHP levels, on average, 3.21 times higher (Cl: $2.91-3.54)$.

Conclusions. Working at the coke plant increases significantly urinary 1-OHP concentration in comparison to nonoccupationally exposed individuals, both for samples collected before and after the working week. Smoking remains a significant source of PAHs exposition, despite the fact that occupational exposure is greater. Health promotion programmes should address both the occupational health risks reduction and smoking prevention.
\end{abstract}

\section{Key words}

1-hydroxypyrene, pyrene, coke plant, cigarettes smoking

\section{INTRODUCTION}

Polycyclic aromatic hydrocarbons (PAHs) are widely distributed in the environment. Among PAHs' sources the incomplete combustion of organic matter, tobacco smoke, and automobile exhausts, as well as natural sources, such as forest fires or volcanic eruptions, should be mentioned [1]. Moreover, food remains an important source of exposition: both as an effect of heat processing, e.g. smoking or grilling, and due to pollution that is adsorbed (from air) onto the surface of fruits or vegetables, absorbed (from soil or water) via roots of plants or consumed/inhaled by animals [2].

PAHs molecules are highly reduced with lipophilic nature what makes them rapidly absorbed by humans. Metabolism of PAHs takes place via the cytochrome $\mathrm{P} 450$ system and results in the production of more electrophilic compounds (epoxides and phenols), which subsequently undergo a conjugation process to produce glucuronides, sulfates or glutathione conjugates [1]. Originally, PAHs are not carcinogenic, but

Address for correspondence: Joanna Zając, Jagiellonian University Medical College, Department Hygiene and Dietetics, Kraków, Poland

e-mail: joanna.jankowska@uj.edu.pl

Received: 15 May 2017; accepted: 10 July 2017; first published on July 18, 2017 some their derivatives develop carcinogenic properties when converted by the body to compounds that can be excreted. It can be said that the carcinogenic effects of PAHs are secondary to their biotransformation [2].

Although PAHs compounds constitute a large family of molecules, not all are considered to pose a high health risk for humans. Among those mentioned on the IARC (International Agency for Research on Cancer) list benzo[a]pyrene, benzo[a] anthracene, benzo[j]fluoranthene, benzo[b]fluoranthene, benzo[k]fluoranthene, dibenzo[a,h]anthracene are the most prominent [3]. Direct harmful health effects of PAHs, such as PAHs-DNA adducts, chromosomal aberrations, cardiac dysfunction, neurotoxic effects or cancers are well documented $[2,4,5]$. Intake of PAHs happens through inhalation or dermal and gastrointestinal routes [2]. Measurement of exposition to PAHs using biomarkers is relatively common. The most commonly used is 1-hydroxypyrene (1-0HP), the main metabolite of pyrene (an abundant constituent of all PAHs mixtures) which correlates with pyrene concentration in air and breathing fraction of particular matter (PM10) [6]. The biological half-life of 1-0HP ranges from $6-35$ hours, with an average of 18 hours [7]. Not only 1-0HP can be used for assessment of exposition during work, but also 
other biomarkers e.g. 3-hydroxybenzo[a]pyrene (3-OHBaP). This metabolite of benzo[a]pyrene, can also be used as an indicator of exposure [2]. Although 3-OHBaP could be treated as biomarker of PAHs' carcinogenic fraction [8], 1-OHP can indirectly evaluate the carcinogenic risk for working individuals. As reported by Apostoli et al., $4.4 \mathrm{mg}$ of 1-OHP per gram of creatinine is connected with a relative risk of 1.3 for lung cancer mortality [6], and by some authors this concentration is considered as a benchmark guideline [9]. Moreover, the usefulness of 1-OHP has been confirmed by many authors $[10,11]$.

As there are no fixed benchmark guidelines, different assessments have been proposed. According to Jongeneelen et al., three benchmark guidelines can be described. The first, for non-occupationally exposed non-smoking individuals is $0.24 \mu \mathrm{mol} / \mathrm{mol}(0.46 \mu \mathrm{g} / \mathrm{g})$ and for smokers $-0.76 \mu \mathrm{mol} /$ $\mathrm{mol}(1.47 \mu \mathrm{g} / \mathrm{g})$. The second, representing the concentration of 1-OHP where among workers no gentoxic effects can be found $-1.4 \mu \mathrm{mol} / \mathrm{mol}(2.7 \mu \mathrm{g} / \mathrm{g})$. And the third benchmark, which represents 1-OHP concentration under occupational exposure, specifically for coke-plant workers - $2.3 \mu \mathrm{mol} /$ mol $(4.4 \mu \mathrm{g} / \mathrm{g})$. However, the publication of Joneneelen from 2014 recommendeda state-of-the-art threshold of 1 -hydroxypyrene in urine as $1.0 \mu \mathrm{mol} / \mathrm{mol}$ creatinine $(1.9$ $\mu \mathrm{g} / \mathrm{g})[12]$

In occupational exposure assessment, according to guidelines, 1-OHP urinary samples should be measured twice: before the beginning of the shift on the first day of the working week (after 2 days without exposure at work) and on the last day of the working week [13].

The aim of presented study was comparison of urinary 1-hydroxypyrene concentrations among coke plant workers (before and after the working week) and among non-exposed individuals from the same area, taking smoking status into consideration.

\section{MATERIALS AND METHOD}

\section{Study population}

The study population included 647 coke plant workers and 206 individuals non-exposed to PAHs at work (control group). The coke plant workers underwent a urinary 1-OHP assay during their routine obligatory annual health screening. The anonymized information on urinary 1-OHP concentration, as well as age and smoking status of the coke plant workers were obtained. The study group covered the whole population of PAH-exposed workers of the coke plant. Among the workers there were 635 men and 12 women; mean age 44 years (min. 18 years, max. 63 years). In the subsequent analysis, the workers were not stratified with respect to gender, due to the under-representation of women Working in conditions of exposition was longer than one year (mean period of exposure to PAHs: 31.5 years).

The control group consisted of volunteers living in the vicinity of the coke plant but not employed therein. The age, smoking status and living area data for the control group was collected using a short survey by a health worker. Control group consisted of 122 women and 84 men aged between 18 - 73 years, average age: 49 years. Both workers and control study participants lived in the same area in small cities (less than 20,000 citizens) or villages, located from about $1 \mathrm{~km}-$ $7 \mathrm{~km}$ from the nearest coke plant battery.
$34 \%$ of workers and $15 \%$ of non-workers declared smoking cigarettes.

\section{Samples collection}

For workers, urine samples were collected twice, according to guidelines [13]: the first before the work shift after two non-working days, and the second at the end of the last day of the working week. In case of control group, samples were collected only once. All the samples were collected between June - December of 2016. Urine samples were collected into polypropylene tubes and immediately frozen at $-20^{\circ} \mathrm{C}$ for a maximum of two weeks for analysis.

\section{Samples treatment}

Analysis of all the samples was performed in the same laboratory using identical methodology. Samples treatment was based on the method described in the publication of Simon et al. [14]. Briefly: $10 \mathrm{ml}$ of urine samples were diluted 1:1 (v/v) with acetate buffer $(0.3 \mathrm{M}, \mathrm{pH}=5)$ and vortexed. Subsequently samples were hydrolyzed using $\beta$-glucuronidase-arylsulphatase. After 16-hours of incubation at $37^{\circ} \mathrm{C}$, samples were vortexed and applied to Solid Phase Extraction columns filled with C18. Adsorbed fraction was subsequently eluted with methanol, evaporated at $37^{\circ} \mathrm{C}$, and dissolved in acetonitrile and water. Samples were applied to a Kinetex C18 $(5 \mu \mathrm{m}, 100 \mathrm{~A}, 150 \times 4.6 \mathrm{~mm})$ column. Elution was carried out in a gradient of acetonitrile (A) and water (B): starting from proportion 0.4:0.6 (A:B) 1:0 (A:B) during the first 25 minutes (changes started after 5 minutes); during last 10 minutes, $\mathrm{A}$ :B proportion returned to the starting proportion (0.4:0.6). Fluorescent detection of 1hydroxypyrene was performed at excitation wavelength $=280 \mathrm{~nm}$ and emission wave- length $=390 \mathrm{~nm}$. Limit of detection (LOD) for 1-hydroxypyrene was established at $0.1 \mu \mathrm{g} / \mathrm{l}$. Calibration was carried out by a standard addition method.

All results were normalized for creatinine. Creatinine was determined photometrically as picrate according to the Jaffé method [15]. In the text, the unit $\mu \mathrm{g} / \mathrm{g}$ means: $\mu \mathrm{g}$ of 1-hydroxypyrene per $1 \mathrm{~g}$ of creatinine. Studies describing the results in units other than $\mu \mathrm{g} / \mathrm{g}$ were cited in original units, together with values recalculated into $\mu \mathrm{g} / \mathrm{g}$ in parenthesis. When needed, for this calculation an average creatinine concentration of $1.30 \mathrm{~g} / \mathrm{l}$ was assumed, which was the average creatinine content in urine among participants of this study. All the measured concentrations were above the method's level of detection.

\section{Statistical analysis}

Concentrations of 1-OHP in urine generally obeyed the log-normal distribution, expressing however some level of distortion. Therefore the non-parametric methods were preferred for data analysis, namely, the U Mann-Whitney test for difference checks, and Spearman correlation for variables dependencies. Where parametric methods were needed, the concentrations were logarithmized, as for example in multiple regression analysis. The confidence intervals (CI) were calculated for $95 \%$ confidence level under the hypothesis of log-normal distribution. Independency of binary variables was checked using 2-sided exact Fisher test.

Statistical analyses were conducted using Statistica 12.0 for Windows. 


\section{RESULTS}

\section{General statistics}

Concentrations of 1-hydrpxypyrene in urine samples for both workers and control group are summarized in Table I. For coke plant workers, there are presented results for both samples gathered: at the beginning of the first working day in the week, and at the end of the last working day in the week. For non-exposed individuals, a single urinary sample was collected and the results are presented for the whole control group, and then repeated stratified with respect to gender.

Table I. Basic statistics of 1-hydroxypyrene concentration in urinary samples of examined people

\begin{tabular}{lccccc}
\hline \multirow{2}{*}{ Category } & \multicolumn{3}{c}{ Workers } & \multicolumn{3}{c}{ Control } \\
\cline { 2 - 6 } & $\begin{array}{c}\text { Before } \\
\text { working week }\end{array}$ & $\begin{array}{c}\text { After } \\
\text { working week }\end{array}$ & All & Women & Men \\
\hline Number of participants & 647 & 640 & 206 & 122 & 84 \\
\hline Mean $[\mu \mathrm{g} / \mathrm{g}]$ & 1.07 & 2.36 & 0.74 & 0.76 & 0.70 \\
\hline SD $[\mu \mathrm{g} / \mathrm{g}]$ & 0.73 & 1.47 & 0.39 & 0.38 & 0.40 \\
\hline Geometric mean $[\mu \mathrm{g} / \mathrm{g}]$ & 0.83 & 2.01 & 0.61 & 0.64 & 0.57 \\
\hline Minimum $[\mu \mathrm{g} / \mathrm{g}]$ & 0.02 & 0.20 & 0.06 & 0.06 & 0.06 \\
\hline 25th percentile $[\mu \mathrm{g} / \mathrm{g}]$ & 0.56 & 1.49 & 0.48 & 0.50 & 0.45 \\
\hline Median $[\mu \mathrm{g} / \mathrm{g}]$ & 0.95 & 2.10 & 0.71 & 0.76 & 0.64 \\
\hline 75th percentile $[\mu \mathrm{g} / \mathrm{g}]$ & 1.36 & 2.84 & 0.95 & 0.97 & 0.92 \\
\hline 95th percentile $[\mu \mathrm{g} / \mathrm{g}]$ & 2.49 & 4.90 & 1.42 & 1.42 & 1.41 \\
\hline Maximum $[\mu \mathrm{g} / \mathrm{g}]$ & 5.13 & 14.89 & 1.94 & 1.93 & 1.94 \\
\hline
\end{tabular}

The difference between 1-OHP concentration in workers' samples before and after the working week was significant: workers after exposition had, on average, 2.43 (CI: 2.31 2.55) times greater concentration of 1-OHP in urine than before exposition (calculated as the geometric mean of concentrations ratios for each working individual). The distribution of measured urinary 1-OHP concentrations in the control group was significantly different from workers pre- and post-exposition samples, as checked using U MannWhitney Test ( $p<10^{-6}$ in both cases). The observed 1-OHP level in workers pre-exposition samples, on average, was 1.35 (CI: 1.21 to 1.51 ) times higher than control, and in postexposition samples, on average, was 3.27 (CI: 2.95 - 3.63) times higher than control (the factor being calculated as ratio of geometric means).

The difference in biomarker concentration between women and men in control group was not statistically significant ( $p=0.14$, as obtained by U Mann-Whitney test). Therefore, in subsequent analysis the control group will not be stratified by gender.

\section{Smoking influence}

For smoking influence analysis, "a some days smoker", as classified by the Centers for Disease Control and Prevention [16], were treated as an ambiguous smoking status and excluded. Moreover, for some participants from the workers group, the data about smoking status was not available. The remaining 582 coke plant workers and 205 control group members with available and unambiguous smoking status were included into subsequent analysis.

Among them, 34\% of workers and 15\% of non-workers declared smoking cigarettes. The difference in the smokers' proportion is significant $\left(p<10^{-5}\right)$ and probably can be attributed to the voluntary nature of the control group recruitment. Among controls, $17 \%$ of women and 11\% of men were smokers, and the hypothesis of smoking being independent of gender cannot be rejected $(p=0.23$ by 2 -sided exact Fisher test).

For the three sets of urine samples (workers' pre-exposition samples, workers' post-exposition samples, and control group) the comparison between non-smokers and smokers was performed using U Mann-Whitney test, and the ratio of geometric means of urinary 1-OHP concentrations between smokers and non-smokers was calculated. The details are presented in Table II.

Table II. 1-hydroxypyrene concentration among smokers and nonsmokers for coke plant workers and control group. Apart from descriptive statistics, the $p$-value of $U$ Mann-Whitney test and the smokers to non-smokers urinary 1-OHP concentration ratio are presented. Participants with ambiguous or unavailable smoking status were excluded

\begin{tabular}{lcccccc}
\hline Group & \multicolumn{2}{c}{$\begin{array}{l}\text { Workers before } \\
\text { working week }\end{array}$} & \multicolumn{2}{c}{$\begin{array}{l}\text { Workers after } \\
\text { working week }\end{array}$} & \multicolumn{2}{c}{ Control } \\
\hline Smoking & No & Yes & No & Yes & No & Yes \\
\hline Number of participants & 386 & 196 & 382 & 194 & 175 & 30 \\
\hline Mean $[\mu \mathrm{g} / \mathrm{g}]$ & 1.03 & 1.19 & 2.32 & 2.52 & 0.73 & 0.82 \\
\hline SD $[\mu \mathrm{g} / \mathrm{g}]$ & 0.75 & 0.69 & 1.58 & 1.33 & 0.39 & 0.41 \\
\hline Geometric mean $[\mu \mathrm{g} / \mathrm{g}]$ & 0.78 & 1.00 & 1.93 & 2.23 & 0.60 & 0.70 \\
\hline Minimum $[\mu \mathrm{g} / \mathrm{g}]$ & 0.02 & 0.15 & 0.20 & 0.27 & 0.06 & 0.18 \\
\hline 25th percentile $[\mu \mathrm{g} / \mathrm{g}]$ & 0.51 & 0.77 & 1.35 & 1.64 & 0.47 & 0.59 \\
\hline Median $[\mu \mathrm{g} / \mathrm{g}]$ & 0.90 & 1.03 & 2.03 & 2.25 & 0.70 & 0.72 \\
\hline 75th percentile $[\mu \mathrm{g} / \mathrm{g}]$ & 1.30 & 1.50 & 2.73 & 2.98 & 0.93 & 1.13 \\
\hline 95th percentile $[\mu \mathrm{g} / \mathrm{g}]$ & 2.44 & 2.54 & 4.92 & 5.08 & 1.42 & 1.63 \\
\hline Maximum $[\mu \mathrm{g} / \mathrm{g}]$ & 5.13 & 4.36 & 14.89 & 8.76 & 1.94 & 1.93 \\
\hline p-value & $0.0011^{*}$ & $0.0123^{*}$ & 0.25 \\
\hline Smokers to non-smokers & \multicolumn{2}{c}{1.28} & & 1.16 & 1.17 \\
1OHP conc. ratio $(\mathrm{Cl})$ & $(1.13-1.44)$ & $(1.05-1.27)$ & $(0.92-1.49)$ \\
\hline
\end{tabular}

* Difference statistically significant

The smoking habit caused a statistically significant difference in 1-OHP concentration in both pre- and postexposition workers' samples. In the pre-exposition sample, the workers had, on average, a $28 \%$ higher concentration of $1-\mathrm{OHP}$, and in the post-exposition samples the rise was by $17 \%$. In the control group, the difference was not statistically significant, but this may be caused by low number of smokers belonging to the control group.

\section{Other variables}

A weak positive Spearman correlation was found in the control group between age and urinary 1-OHP level (correlation coefficient: $\rho=0.19$ ); however, no such correlation was found among workers $(\rho=0.002)$. No significant correlation was found among the control group between urinary 1-OHP concentration and the distance between their place of residence and the coke plant $(\rho=0.07)$. Smokers and nonsmokers did not differ in age, both in control group $(p=0.39)$ and among workers $(p=0.21)$.

\section{Multiple regression analysis}

Multiple regression was performed to distinguish and quantify the influence of cigarette smoking and occupational $\mathrm{PAH}$ exposition on the urinary 1-OHP levels. The logarithm of 
urinary 1-OHP concentration was chosen to be the dependent variable. For workers, the post-exposition samples were used to reflect the actual occupational exposure. Taking logarithm assures that the statistical errors to the dependent variable are homogeneously distributed across the whole range of values (homoscedasticity), which is a necessary condition for regression analysis. Two binary variables were chosen as the dependent (explanatory) variables of the regression model: the smoking status $(0=$ non-smoker; $1=$ smoker $)$ and working status $(0=$ control group; $1=$ coke plant worker). Age was not included as an explanatory variable because of its different Spearman correlations with 1-OHP level among controls and workers (as explained before), as well as because of the statistically significant age difference between controls and workers that would introduce covariance between explanatory variables. Table III shows the multiple regression results.

Table III. Results of multiple regression on logarithm of 1-OHP urinary concentration (with post-exposure results for workers) with respect to two binary variables: smoking status and working status*. Participants with ambiguous or unavailable smoking status were excluded

\begin{tabular}{lccr}
\hline & Intercept term $\pm \mathrm{SE}$ & $\mathrm{GM}[\mu \mathrm{g} / \mathrm{g}](\mathrm{Cl})$ & \\
\hline $\begin{array}{l}\text { Value for } \\
\text { non-smoking controls }\end{array}$ & $-0.22 \pm 0.02$ & $0.60(\mathrm{Cl}: 0.55-0.65)$ & \\
\hline & Coefficient $\pm \mathrm{SE}$ & Multiplicative factor $(\mathrm{Cl})$ & $\mathrm{p}$-value \\
\hline Smokers/non-smokers & $0.06 \pm 0.02$ & $1.16(\mathrm{Cl}: 1.05-1.28)$ & $0.002837 \dagger$ \\
\hline Workers/Control & $0.51 \pm 0.02$ & $3.21(\mathrm{Cl}: 2.91-3.54)$ & $<10^{-6} \dagger$ \\
\hline
\end{tabular}

*The first column represents the raw regression coefficients. In the second column the same coefficients are exponentiated to remove the effect of logarithm. In that way the intercept term becomes the geometric mean of urinary 1-OHP concentration for non-smoking controls, and the other coefficients represent the multiplicative factors by which the concentration rises when the individual is smoking or working in a coke plant, respectively. The $p$-value represents the the individual is smoking or working in a coke plant, respectively. The $p$-value represents the
probability of multiplicative factor being less or equal to 1. GM-geometric mean, SE-standard error, $\mathrm{Cl}-95 \%$ confidence interval.

† Difference statistically significant

Briefly, the results are that the geometric mean for nonsmoking individuals not exposed occupationally to PAHs is expected to be 0.60 (CI: $0.55-0.65) \mu \mathrm{g} / \mathrm{g}$. Smoking cigarettes induces a rise in urinary 1-OHP level by a factor of 1.16 , on average (CI: $1.05-1.28)$, and working for a whole working week at the coke plant made urinary 1-OHP levels, on average, 3.21 times higher (CI: 2.91 - 3.54). For smoking coke plant workers both factors combine.

\section{DISCUSSION}

An increased risk of lung cancer, occupational fatigue or cardiovascular diseases were reported not only among workers occupationally-exposed to PAHs, but also among nearest neighbourhood of pollution source; it is therefore crucial to monitor areas located near coke plants $[17,18,19]$. A study by Campo et al investigated 1-OHP concentration in three groups: coke-oven workers, the population living near the plant - up to $2 \mathrm{~km}$ and about $50 \mathrm{~km}$ away from the plant, and found no statistically significant differences between those living near and farther away from the coke plant [20]. Similarly, in the presented study no correlation for biomarker concentration and distance from the coke plant battery was found.

Contact with PAHs compounds during the work week significantly affects 1-OHP concentration in urine samples as described in the presented work and in other studies
[21]. Simultaneously, the results of 1-OHP among workers measured before contact with PAHs at work was significantly higher than in the control group (median: $0.95 \mu \mathrm{g} / \mathrm{g}$ vs. $0.71 \mu \mathrm{g} / \mathrm{g}$; geometric mean: $1.07 \mu \mathrm{g} / \mathrm{g}$ vs $0.74 \mu \mathrm{g} / \mathrm{g}$ ) as preshift samples describe the contribution of the longer-lived compounds [22]. According to the literature, 1-OHP has wide range of half-life time, from 6 - 35 hours [7], and some literature data report a longer half-life time of 16 days [23].

Results obtained for the control in presented study are about one magnitude higher than those described by Huang, who reported the overall geometric mean concentration for 1-OHP in the USA as $74.2 \mathrm{ng} / \mathrm{g}$ (CI: $64.1-85.9 \mathrm{ng} / \mathrm{g}$ ) and found no statistically significant differences for age or gender [22]. Similarly, in presented study there were no statistically significant differences caused by gender. However, other authors have reported a statistically significant disproportion between genders, higher for women: $0.5 \mu \mathrm{mol} / \mathrm{mol}(0.96 \mu \mathrm{g} / \mathrm{g})$ vs. $0.34 \mu \mathrm{mol} / \mathrm{mol}(0.66 \mu \mathrm{g} / \mathrm{g})$ for men, although all the women were non-smokers [24]. This observation was attributed to the amount of time spent in the kitchen for frying and other types of cooking connected with formation of PAHs compounds, and as expected, this difference disappeared among children [25]. The paradox of an inhaled dose of pyrene among nonsmokers being several times lower than the daily urine 1-OHP excretion was reported by Rubino et al, and it was suggested that this may be due to the slow release of pyrene from the soot deposit in the lung alveoli that was trapped in the lungs during life [26]. In the presented study, alththough not statistically significant, slightly higher results were noted for women than for men (geometric means: $0.57 \mu \mathrm{g} / \mathrm{g}$ for men vs. $0.64 \mu \mathrm{g} / \mathrm{g}$ for women). Similarly, Bertolome et al. described higher, but not statistically significant, 1-OHP concentration for women [27]. On the other hand, a study published by Yamano et al for a non-exposed group reported a geometric mean equal to $0.52 \mu \mathrm{mol} / \mathrm{mol}(1 \mu \mathrm{g} / \mathrm{g})$, which is higher than the presented results for both groups, coke plant workers: $0.83 \mu \mathrm{g} / \mathrm{g}$ and control: $0.61 \mu \mathrm{g} / \mathrm{g}$. Simultaneously, higher values were noted for the $95^{\text {th }}$ percentile in both groups [10].

Smoking status, according to metanalyses performed by Ciarrocca et al., is an important confounder, mainly for low occupationally-exposed individuals. Ciarrocca et al. suggested that smoking reduces the difference in biomarker concentration between those occupationally- exposed and non-exposed [2], although the authors describe statistically significant differences between smokers and non-smokers for those exposed to PAHs and those not exposed. In the case of the presented data on coke plant workers who are considered as being highly exposed, using multiple regression, smoking combines significantly with work exposure: as smoking induces a rise in 1-OHP concentration by $16 \%$, on average (CI: $5 \%-28 \%$ ), and as exposition during work induces, on average, a 3.21-fold rise in biomarker concentration (CI: 2.91 - 3.54). On the other hand, in a study by Talaska, the discrepancy between smoking and non-smoking coke plant workers was not statistically significant for 1-OHP concentration and DNA addicts. Such an observation is unusual as 50\% of the studied population $(n=32)$ were smoking workers. Stratification according to exposition (supervisors and sideproduct area workers) gave only a small, still insignificant, difference [23]. 


\section{CONCLUSIONS}

1. Working at a coke plant significantly increases urinary 1-OHP concentration in comparison to nonoccupationally-exposed individuals, both for samples collected before and after the working week. This indicates that samples collected at the beginning of the working week are not suitable in assessment of the workers' background (non-occupational) exposition.

2. Despite the fact that occupational exposure induces a much greater influence on urinary 1-OHP concentrations than cigarettes smoking, the latter's effect is still significant. Therefore, the negative health impact of tobacco smoking on coke plant workers should not be neglected. Health promotion programmes should address both the occupational health risks reduction and smoking prevention.

\section{REFERENCES}

1. Samanta SK, Singh OV, Jain RK. Polycyclic aromatic hydrocarbons: environmental pollution and bioremediation. Trends Biotechnol. 2002; 20(6): 243-248.

2. Ciarrocca M, Rosati MV, Tomei F, Capozzella A, Andreozzi G, Tomei G, Bacaloni A, Casale T, Andre 'JC, Fioravanti M, Cuartas MF, Caciari T. Is urinary 1-hydroxypyrene a valid biomarker for exposure to air pollution in outdoor workers? A meta-analysis. J Exp Sci Env Epidemiol. 2014; 24:17-26.

3. http://monographs.iarc.fr/ENG/Classification/latest_classif.php (accessed: 04.04.2017).

4. Chen S-C, Liao C-M. Health risk assessment on human exposed to environmental polycyclic aromatic hydrocarbons pollution sources. Sci Total Environ. 2006; 366:112-123.

5. Lee MS, Magari S, Christiani DC. Cardiac autonomic dysfunction from occupational exposure to polycyclic aromatic hydrocarbons. Occup Environ Med. 2010; 68: 474-478.

6. Apostoli P, Porru S. Biological monitoring and risk assessment. In: Advances in Occupational Medicine vol. 1. Maugeri Foundation Books: Pavia, 2000. pp 227-233.

7. Ifegwu C, Osunjaye K, Fashogbon F, Oke K, Adeniyi A, Anyakora C. Urinary 1-hydroxypyrene as a biomarker to carcinogenic polycyclic aromatic hydrocarbon exposure. Biomarkers Cancer. 2012; 4:7-17.

8. Förster K, Preuss R, Roßbach B, Brüning T, Angerer J, Simon P. 3-hydroxybenzo[a]pyrene in the urine of workers with occupational exposure to polycyclic aromatic hydrocarbons in different industries. Occup Environ Med. 2008; 65:224-229.

9. Jongeneelen FJ. Benchmark guideline for urinary 1-hydroxypyrene as biomarker of occupational exposure to polycyclic aromatic hydrocarbons. Ann Occup Hyg. 2001; 45(1): 3-13.

10. Yamano, Y., Hara, K., Ichiba, M, Hanaoka T, Pan G, Nakadate T. Urinary 1-hydroxypyrene as a comprehensive carcinogenic biomarker of exposure to polycyclic aromatic hydrocarbons: a cross-sectional study of coke oven workers in China. Arch Occup Environ Health. 2014; 87: 705-713.

11. Käfferlein, H.U., Marczynski, B., Simon, P, Angerer J, Rihs H-P, Wilhelm M, Straif K, Pesch B, Brüning T. Internal exposure to carcinogenic polycyclic aromatic hydrocarbons and DNA damage: a null result in brief. Arch Toxicol. 2012; 86: 1317 - 1321.

12. Jongeneelen FJ. A guidance value of 1-hydroxypyrene in urine in view of acceptable occupational exposure to polycyclic aromatic hydrocarbons. Toxicol Let. 2014; 231 (2):239-248.

13. http://www.inrs.fr/publications/bdd/biotox/dosage. html?refINRS=Dosage_151 (accessed: 04.04.2017)

14. Simon P, Morele Y, Delsaut P, Nicot T. Automated column-switching high-performanceliquid chromatography method for the determination of 1-hydroxypyrene in human urine. J Chromatogr B Biomed Sci Appl. 1999; 732: 91-101.

15. Taussky H. A micro-colorimetric determination of creatinine in urine by Jaffe' reaction. J Biol Chem. 1954; 208: 853-861.

16. https://www.cdc.gov/nchs/nhis/tobacco/tobacco_glossary.htm (accessed: 19.04.2017)

17. Ahn YS, Park RM, Stayner L, Kang SK, Jang JK. Cancer morbidity in iron and steel workers in Korea. Am J Ind Med. 2006; 49(8):647-657.

18. Pless-Mulloli T, Phillimore P, Moffatt S, Bhopal R, Foy C, Dunn C, Tate J. Lung cancer, proximity to industry and poverty in northeast England. Environ Health Perspect, 1998, 106(4):189-196.

19. Rafiei M, Gadgil A, Patil H, Jamir T. Evaluation of health consequences of air pollution induced by Beam Rolling Mills Factory (Iran), PESD. 2015; 8(2):63-73.

20. Campo L, Vimercati L, Carrus A, Bisceglia L, Pesatori AC, Bertazzi PA, Assennato G, Fustinoni S. Environmental and biological monitoring of PAHs exposure in coke-oven workers at the Taranto plant compared to two groups from the general population of Apulia, Italy. Med Lav 2012; 103, 5: 347-360.

21. Hansen ÅM, Mathiesen L, Pedersen M, Knudsen LE. Urinary 1-hydroxypyrene (1-HP) in environmental and occupational studies-A review. Int J Hygiene Environ Health. 2008; 211: 471-503.

22. Huang W, Grainger J, Patterson DG, Turner WE, Caudill SP, Needham LL, Pirkle JR, Sampson EJ. Comparison of 1-hydroxypyrene exposure in the US population with that in occupational exposure studies. Int Arch Occup Environ Health. 2004; 77:491.

23. Talaska G, Thoroman J, Schuman B, Käfferlein HU. Biomarkers of polycyclic aromatic hydrocarbon exposure in European coke oven worker. Toxicol Let. 2014; 231: 213-216.

24. Chen B, Hu Y, Jin T, Zheng L, Wang Q, Shen Y, Zhou Y. Higher urinary 1 -hydroxypyrene concentration is associated with cooking practice in a Chinese population. Toxicol Lett. 2007; 171(3): 119-125.

25. Mucha AP, Hryhorczuk D, Serdyuk A, Nakonechny J, Zvinchuk A, Erdal S, Caudill M, Scheff P, Lukyanova E, Shkiryak-Nyzhnyk $\mathrm{Z}$, Chislovska N. Urinary 1-hydroxypyrene as a biomarker of PAH exposure in 3-year-old Ukrainian children. Environ Health Persp. 2006; 114: 603-609.

26. Rubino FM, Verduci C, Buratti M, Fustinoni S, Neri L, Brambilla G. Biomonitoring of exposure to $\mathrm{PAH}$ : the pyrene vs. 1-hydroxypyrene paradox. G Ital Med Lav Ergon. 2004; 26(4):98-99.

27. Bartolomé M, Ramos JJ, Cutanda F, Huetos O, Esteban M, RuizMoraga M, Calvo E, Pérez-Gómez B, González O, BIOAMBIENT. ES, Castaño A. Urinary polycyclic aromatic hydrocarbon metabolites levels in a representative sample of the Spanish adult population: The BIOAMBIENT.ES project. Chemosphere. 2015; 135: 436-446. 